\title{
HUBUNGAN PERILAKU HIDUP SEHAT DENGAN TINGKAT KESEGARAN JASMANI SISWA KELAS VIII SMP NEGERI 16 KOTA BENGKULU
}

\author{
Fitri Ropita Sari
}

PENJAS FKIP UNIB, e-mail: Fitriropitasari029@gmail.com

\section{Sugiyanto}

Universitas Bengkulu

\section{Syafrial}

Universitas Bengkulu

\begin{abstract}
Abstrak
Perilaku seorang siswa sangat berpengaruh terhadap tingkatkebugaran jasmani, mengkonsumsi makanan sesuai dengan porsi gizi yang dianjurkan, berperilaku hidup sehat yang teratur, menjaga kebersihan diri, mengetahui jenis penyakit, merupakan tolak ukur keberhasilan pencapaian prestasi. Tujuan penelitian ini adalah untuk mengetahui hubungan perilaku hidup sehat dengan tingkat kesegaran jasmani siswa kelas VIII SMP Negeri 16 Kota Bengkulu Tahun Ajaran 2017/2018. Jenis penelitian ini adalah deskriptif kuantitatif . Populasi sebanyak 200 siswa dengan sampel random sebesar 40 siswa kelas VIII SMP Negeri 16 Kota Bengkulu. Untuk menganalisis data peneliti menggunakan data sekunder dengan instrument angket (kuisioner) dan TKJI. Hasil analisis data diperoleh bahwa nilai rata-rata perilaku hidup sehat siswa kelas VIII SMP Negeri 16 Kota Bengkulu berada dalam katagori baik dengan skor rata-rata = 91,75 dan nilai rata-rata kesegaran jasmani siswa kelas VIII SMP Negeri 16 Kota Bengkulu berada dalam kategori Sedang dengan nilai skor rata-rata $=15,725$. Analisis menggunakan rumus Product Moment $(r)$ dengan hasil didapat nilai $r$ sebesar 0,6820 tersebut kemudian dikonsultasikan dengan angka kritik product moment dengan $\mathrm{N}=40$. Pada tabel diketahui $r$ tabel dengan taraf signifikan $1 \%$ sebesar 0,403 dengan demikian maka $r$ hitung lebih besar dari pada $r$ tabel atau 0,6820 0,403 dan $r$ 0,682 ini dapat dilihat pada tabel pedoman interpretasi korelasi dengan tingkat hubungan berada pada 0,60 - 0,789 yang berarti ada hubungan antara perilaku hidup sehat dengan tingkat kesegaran jasmani siswa kelas VIII SMP Negeri 16 Kota Bengkulu dengan tingkat hubungan dalam kategori kuat.
\end{abstract}

Kata Kunci : Perilaku Hidup Sehat, Kesegaran Jasmani

\section{Abstract}

Behavior of a student was very influential on the level of Physical Fitness, consuming food in accordance with the recommended nutritional portion, regular healthy living behavior, maintaining personal hygiene, knowing the type of disease was a measure 
of achievement success. The purpose of this study was to determine the relationship of healthy living behavior with the level of physical fitness of VIII Grade students of junior high school 16 Bengkulu City in Year 2017/2018. This type of research was descriptive quantitative. The population of this research was 200 students with 40 students as a random sample of VIII Grade students of junior high school 16 Bengkulu City. To analyze the data the researcher used secondary data with questionnaire instrument and TKJI. The result of data analysis showed that the mean value of healthy life behavior of the VIII Grade students of SMP Negeri 16 Bengkulu city was in good category with the average value $=91.75$ and the average value of physical fitness of students was in moderate category with average value $=15,725$. The researcher used Analysis Product Moment formula $(r)$ with result $r$ equal to 0,6820 then consulted with product moment table with $N=40$. In the table known $r$ table with a significant level of $1 \%$ of 0.403 thus the calculated $r$ was greater than the $r$ table or 0.6820> 0.403 and $r 0.682$ could be seen in the correlation interpretation guidance table with the level of relationship is at 0.60-0,789 which means there was a relation ship between the behavior of healthy living with the level of physical fitness of VIII Grade students of junior high school 16 Bengkulu City with the level of relationship in the category strong.

Keywords: Healthy Life Behavior, Physical Fitness

\section{PENDAHULUAN}

Undang-Undang Sistem

Pendidikan Nasional No.20 Tahun 2003 mengamanatkan bahwa Pendidikan Nasional berfungsi untuk mengembangkan kemampuan dan watak serta peradaban bangsa yang bermartabat dalam rangka mencerdaskan kehidupan bangsa menjadi manusia yang beriman dan bertaqwa kepada Tuhan Yang Maha Esa, berakhlak Mulia, sehat, berilmu, cakap, kreatif, mandiri dan menjadi warga Negara yang berdemokratis dan bertanggung jawab. Pembinaan kesegaran jasmani merupakan bagian dari upaya meningkatkan kualitas sumber daya manusia yang diarahkan pada peningkatan kondisi kesehatan fisik, mental dan rohani bangsa Indonesia.

SMP Negeri 16 Kota Bengkulu merupakan salah satu dari sekian banyaknya wadah pendidkan formal yang ada di Provinsi Bengkulu, yang telah meraih sebagai predikat sekolah sehat, sebagai sekolah sehat diharapkan sanitasi sekolah bagus, siswa mengetahui dan mendapatkan pengetahuan kesehatan yang cukup, mempunyai tim medis, mempunyai kader kesehatan remaja serta diharapkan mempunyai kesegaran jasmani yang baik, tentunya hal ini tidak dapat lepas dari semua pihak baik yang datangnya dari dalam maupun luar sekolah. Peningkatan kesegaran fisik dapat melalui 
pembinaan kesegaran jasmani, pembinaan kesegaran jasmani merupakan faktor yang penting dalam peningkatan kualitas fisik, oleh karena itu pembinaan kesegaran jasmani merupakan hal yang diperlukan sejak usia sekolah melalui pendidikan jasmani. Kendati demikian nilai-nilai olahraga belum dipahami secara menyeluruh oleh masyarakat dan olahraga belum dipandang sebagai kebutuhan hidup. Kondisi ini tercermin dari rendahnya kualitas kesegaran jasmani masyarakat yang belum mencapai taraf yang diharapkan. Kondisi perilaku hidup sehat harus dibangun dan diimbangi dengan peningkatan kesegaran jasmani sehingga memungkinkan seseorang memiliki tingkat daya tahan untuk mampu melakukan aktivitas sehari-hari tanpa merasa lelah dan menghasilkan kerja fisik atau non fisik secara maksimal.

Menurut Widiastuti (2011:13) Pentingnya kesegaran jasmani bagi anak usia sekolah antara lain dapat meningktkan kemampuan organ tubuh, sosial emosional, sportivitas, dan semangat kompetisi. Selain itu kondisi kesegaran jasmani siswa yang baik juga akan menentukan status kesehatan seseorang sehingga tidak mudah sakit, bertenaga dan disiplin dalam beraktifitas sehari-hari.

Pemeliharaan kesehatan seseoarang tidak cukup dengan berolahraga saja, namun faktor lain juga mempengaruhi kesehatan, antara lain perilaku terhadap kebiasaan mengkonsumsi makanan sehat, menjaga kebersihan diri, hidup yang teratur dan pengetahuan mengenai kesehatan. Menurut Rusli Ibrahim (2003:13) agar seseorang tetap sehat, ia harus mampu menjaga kebersihan dan kesehatan diri pribadinya dan lingkungannya.

Menurut Sarwoto dan Bambang Soetedjo (1993:188) masa sekolah adalah masa yang tepat untuk menanamkan kebiasaan hidup sehat dengan harapan agar mereka dapat meneruskan dan mempengaruhi lingkunganya pada saat sekarang dan dimasa yang akan datang karena masyarakat yang akan datang merupakan salah satu hasil dari pengertian, sikap, perilaku dan kebiasaan hidup sehat yang dimiliki anak pada waktu sekarang. Jika dilihat dari segi kesehatan baik itu dari segi makanan, kebersihan diri, hidup yang teratur dan pengetahuan mengenai sakit dan penyakitnya maka salah satu faktor kesehatan merupakan penunjang untuk meningkatkan prestasi siswa.

Perilaku seorang siswa sangat berpengaruh terhadap tingkat prestasi yang dicapai, mengkonsumsi makanan sesuai dengan porsi gizi yang dianjurkan, berperilaku sehat yang teratur, menjaga kebersihan diri, mengetahui penyakit, merupakan tolak ukur keberhasilan prestasi. Jika siswa sudah mengetahui dan melaksanakan perilaku hidup sehat ini 
maka diharapkan dapat mewujudkan tujuan dari Undang-Undang Sistem Pendidikan Nasional No.20 Tahun 2003.

Sehubungan dengan hal tersebut, siswa kelas VIII SMP Negeri 16 Kota Bengkulu harus mengetahui faktor-faktor yang menyebabkan tercapainya kesegaran jasmani siswa yaitu perilaku terhadap kebiasaan makan, hidup yang teratur, kebersihan diri dan pengetahuan tentang penyakit.

Berdasarkan latar belakang yang disampaikan diatas, penulis tertarik untuk mengetahui bagaimana "Hubungan Perilaku Hidup Sehat Terhadap Tingkat Kesegaran Jasamani Siswa Kelas VIII SMP Negri 16 Kota Bengkulu".

\section{METODE}

Penelitian ini berjenis penelitian Kuantitatif Deskriptif .

Populasi dalam penelitian ini adalah seluruh siswa Kelas VIII SMP Negeri 16 Kota Bengkulu, teknik pengambilan sampel dalam penelitian ini menggunakan teknik simple random sampling yang berarti pengambilan sampel dilakukan dengan cara acak. Berdasarkan teknik sampel di atas maka sampel dalam penelitian ini berjumlah 40 orang.

Dalam penelitian ini terdapat dua variabel yaitu variabel bebas dan variabel terikat. Variabel bebas dalam penelitian ini adalah perilaku hidup sehat siswa kelas VIII dan variabel terikat nya adalah kesegaran jasmani sisswa kelas VIII. Tekhnik pengumpulan data perilaku hidup sehat menggunakan Angket dengan validitas content validity kemudian untuk kesegaran jasmani menggunakan Tes Kesegaran Jasmani Indonesia (TKJI) (Widiastuti).

\section{HASIL DAN PEMBAHASAN}

1) Uji Prasarat.

a. Uji Normalitas

Tabel 1 One-Sample KolmogorovSmirnov Test

\begin{tabular}{l|r} 
& $\begin{array}{l}\text { Perilaku } \\
\text { Hidup } \\
\text { Sehat }\end{array}$ \\
\hline $\mathrm{N}$ & 40 \\
Normal & 91,75 \\
Parameters... & 3654 \\
Mean & .170 \\
& .130 \\
Std. Deviation & -.170 \\
Most Extreme & .761 \\
Differences & 6.08 \\
Absolute & \\
& \\
Positive & \\
Negative & \\
Kolmogorov-Smirnov & \\
Z & \\
Asymp.Sig.(2-tailed) &
\end{tabular}

Dari data diatas diketahui variabel perilaku hidup sehat mendapat nilai t hitung 6,08 dengan t tabel 1\% 15,086 maka nilai t hitung lebih kecil dari $t$ tabel skor data 
perilaku hidup sehat berdistribusi Normal .

b. Uji Homogenitas

Tabel 2. One-Sample KolmogorovSmirnov Test

\begin{tabular}{l|r} 
& \multicolumn{2}{|l}{$\begin{array}{l}\text { Kesegaran } \\
\text { Jasmani }\end{array}$} \\
\hline $\mathrm{N}$ & 40 \\
Normal & 15,72 \\
Parameters ${ }^{.}$. & 629 \\
Mean & .170 \\
& .130 \\
Std. Deviation & -.170 \\
Most Extreme & .761 \\
Differences & 5.76 \\
Absolute & \\
& \\
Positive & \\
& \\
Negative & \\
Kolmogorov-Smirnov & \\
Z & \\
Asymp.Sig.(2-tailed) &
\end{tabular}

Dari data diatas diketahui variabel kesegaran jasmani mendapat nilai t hitung 5,76 dengan t tabel $1 \%$ 15,086 maka nilai t hitung lebih kecil dari $\mathrm{t}$ tabel maka data kesegaran jasmani berdistribusi Normal.

c) Uji Homogenitas perilaku hidup sehat dan kesegaran jasmani

Tabel 3 Test Homogenity of Variance

\begin{tabular}{l|l|l|l}
$\begin{array}{l}\text { Levene } \\
\text { Statistic }\end{array}$ & $\mathbf{d f 1}$ & $\mathbf{d f 2}$ & Sig. \\
\hline 3.806 & 12 & 28 & 2.353
\end{tabular}

Dari data diatas diketahui bahwa hasil dari uji homogenitas variabel perilaku hidup sehat dengan tingkat kesegaran jasmani siswa kelas VIII SMP Negeri 16 Kota Bengkulu adalah $t$ hitung 2,353 dengan $t$ tabel $1 \%$ yaitu 6,635. Hal ini dapat dinyatakan bahwa nilai $2,353<6,635$ sehingga nilai data perilaku hidup sehat dengan tingkat kesegaran jasmani siswa kelas VIII SMP Negeri 16 Kota Bengkulu mempunyai nilai yang Homogen.

2) Analisis Perilaku Hidup Sehat Hasil mean perilaku hidup sehat siswa kelas VIII SMP Negeri 16 Kota Bengkulu adalah 91,75 dikonsultasikan pada tabel 2 yaitu tabel interpretasi skor berdasarkan interval kriteria penilaian ternyata terletak antara 75- 99,99 dengan klasifikasi baik, dengan demikian dapat disimpulkan bahwa perilaku hidup sehat siswa kelas VIII SMP Negeri 16 Kota Bengkulu baik.

\section{3) Analisis Kesegaran Jasmani}

Kesegaran jasmani siswa SMP Negeri 16 Kota Bengkulu berkategori sedang karena meanya 15,75 dikonsultasikan pada tabel 5 yaitu tabel norma tes kesegaran jasmani berada pada nilai 14-17 . Kesegaran jasmani dibutuhkan bagi seorang siswa yang aktif dalam belajar, siswa memerlukan stamina tubuh, karena dengan tubuh yang segar dan sehat akan menimbulkan gairah belajar yang 
tinggi pula yang pada akhirnya dapat mendapatkan prestasi yang baik.

4) Analisis Hubungan Perilaku Hidup Sehat Dengan Tingkat Kesegaran Jasmani Sisswa Kelas VIII SMPN 16 Kota Bengkulu

Hasil perhitungan korelasi $(r)$ didapat nilai $r$ sebesar 0,6820. Hasil tersebut dikonsultasikan dengan tabel Person Product Moment dengan $\mathrm{N}=$ 40. Pada tabel diketahui $r$ tabel dengan taraf signifikat $1 \%$ sebesar 0 , 403 dengan demikian maka $r$ hitung lebih besar dari $r$ tabel atau 0,6820 > 0,403. Oleh karena itu maka HO ditolak dan Ha diterima, yang berarti ada hubungan antara perilaku hidup sehat dengan tingkat kesegaran jasmani siswa kelas VIII SMP Negeri 16 Kota Bengkulu.

Kemudian untuk melihat keeratan hubungan dikonsultasikan pada tabel 6 yaitu tabel pedoman interpretasi korelasi dengan tingkat hubungan didapat hasil sebagai berikut, koefisien korelasi (rxy) sebesar 0,6820 jika dikonfirmasikan pada tabel interprentasi korelasi maka dapat dilihat bahwa tingkat hubungan interval korelasi berada pada 0,60 - 0,789, dengan demikian dapat ditarik kesimpulkan bahwa ada hubungan yang kuat antara perilaku hidup sehat dengan tingkat kesegaran jasmani siswa kelas VII SMP Negeri 16 Kota Bengkulu.

\section{Simpulan}

Dari data yang diperoleh dalam penelitian ini, dapa disimpulkan bahwa ada hubungan perilaku hidup sehat dengan tingkat kesegaran jasmani siswa kelas VIII SMP Negeri 16 Kota Bengkulu. Hubungan ini dibuktikan dengan hasil perhitungan korelasi antara variabel $X$ dan $Y$ yaitu sebessar 0,6820 angka tersebut setelah dikonsultasikan dengan tabel Person Product Moment dengan $\mathrm{N}=40$ ternyata $r$ hitung lebih besar dari $r$ tabel dimana taraf signifikat $1 \%(0,6820>0,403)$, setelah dikonsultasikan pada pedoman interpretasi dengan tingkat hubungan menurut Sugiyono (2016:184) hubungan perilaku hidup sehat dengan tingkat kesegaran jasmani siswa kelas VIII SMP Negeri 16 Kota Bengkulu berada pada interval korelasi 0,60-0,789 dengan tingkat hubungan dalam kategori kuat.

\section{Saran}

1. Kepada siswa untuk lebih meningkatkan pengetahuan tentang perilaku hidup sehat, dan kesegaran jasmani, karena keduanya memiliki hubungan yang positif dan tidak dapat ditinggalkan keduanya haruslah seimbang. Dengan perilaku hidup sehat dan kesegaran jasmani yang baik akan meningkatkan prestasi baik dibidang akademik maupun dibidang lainnya. 
2. Pada guru untuk memberikan penjelasan kepada siswa tentang pentingnya perilaku hidup sehat dengan mengkonsumsi makanan yang bergizi dan seimbang, sarapan sebelum berangkat sekolah, tidak merokok, berolahraga secara teratur untuk meningkatkan kesegaran jasmani dan stamina, karena didalam tubuh yang sehat terdapat jiwa yangt kuat.

3. Kepada pihak pemerintah agar memberikan penyuluhan kesekolah-sekolah tentang perilaku hidup sehat baik dengan metode ceramah, memutar film yang betemakan perilaku hidup sehat, maupun melakukan demonstrasi dan dapat juga dengan melakukan penerbitkan poster yang berkaitan dengan perilaku hidup sehat.

\section{DAFTAR PUSTAKA}

Afandi Sufuan(2015)Kamus Besar Bahasa Indonesia. Sendang Ilmu.Solo

Ari Kunto(2011)Metode Penelitian Aplikasi Dan Penerapan.Reneka Cipta.Jakarta.

Amin Agus Sulastiano.(2009)Jurnal Ilmiah Pendidikan Jasmani Dan Kesehatan.Pusat Pengembangan Kualitas Jasmani Kementerian Pendidikan Nasional.Jakarta

Hanif Farida Perdana(2015)Sehat itu (Bisa) Murah.Jayakarsa.
Ichsan(2007)Pendidikan

Kesehatan.Debdikbud.Yogyakarta

Irianto Koes(2014)Panduan Kesehatan Keluarga.Yayasan essential Medica.Yogyakarta

Jiwono(1996)Kesegaran

Jasmani.Depdikbud.Yogyakarta

Moefoedz Ichan(2007)Pendidikan Kesehatan Bagian Dari Promosi Kesehatan.Sendang Ilmu.Solo

Mutohir Totho Cholik dan Maksum Ali(2007)Sport Development Index (Konseop,Metodologi dan aplikasi).Indeks.Jakarta

Richard(2011)Kesegaran Jasmani. PT Citra Unggul Laksana.Jakarta

Roji(2001).Hidup Sehat,Kineja Melejit.PT Saufa.Yogyakarta

Rusli Ibrahim(200).Lingkungan Hidup dan Kesehatan.Depdiknas. Jakarta

Santosa Giriwijoyo dan Komaryah Lilis(2007)Ilmu Kesehatan

Olahraga(Sport Medicine).UPI.Bandung

Santosa Giriwijoyo dan Zafar Sidik Didik(2014)ILMU FAAL Olahraga (Fisiologi Olahraga).Remaja Rosdakarya Bandung

Sarwoto dan Soetedjo Bambang (1993)Pendidikan Kesehtan dan P3P.Jakarta. 
KINESTETIK : Jurnal Ilmiah Pendidikan Jasmani,2 (1) 2018.

Tangkudung, James. (2012).

Kepelatihan Olahraga

Pembinaan Prestasi Olahraga.

Jakarta: Cerdas jaya ,(2016).Macam-macam Metodologi Penelitian. Jakarta:

Lensa Media Pustaka Indonesia 